"Australia Telescope", the other the optical astronomers" "Starlab" project.

With the news that the Australian Telescope has been funded to the tune of A $\$ 25$ million, CSIRO can now proceed to develop a continental-scale, radio-linked interferometer network. When completed in 6 years' time, this should provide a Southern Hemisphere radio facility comparable to the most sophisticated interferometers in the north, complementing the activities in the optical and infrared bands of the Anglo-Australian Telescope.

The Australian Telescope will consist of a linear array of five 22-metre dishes at Culgoora in New South Wales, a 22-metre dish at Siding Spring (the site of the AngloAustralian Telescope) and a 64-metre dish at Parkes. The total array will be equivalent to a dish $300 \mathrm{~km}$ across with a revolution of 0.1 seconds of arc - comparable to the US/European space telescope. It is also proposed that five other sites, covering much of the continent, can be radio-linked to the network, improving the resolution to one-thousandth of a second of arc.

The Starlab project has not been so fortunate. This joint Canadian, US, Australian scheme aims to place a 1-metre telescope in Earth-orbit by 1989. Australia's contribution was to have been the instrument package for the telescope. At this stage the government is not prepared to commit the full A\$28 million that would be necessary if Australia is to participate. But it is keeping the project alive by providing A $\$ 3.3$ million to local industry for some preliminary work.

Australian postgraduate research scholars were another notable group to gain in the budget. About one third of all full-time research students enrolled for higher degrees are supported on these scholarships. They have just been awarded a 50 per cent salary increase, presumably in recognition of the importance of their work as integral members of university research teams, and as Australia's future research scientists. Although this increase sounds impressive, the salary of a scholar has now only climbed from below the official poverty line to a generous $A \$ 40$ a week above (A $\$ 6,850$ a year). This is still less than half the average wage and no doubt a measure of the high esteem in which many Australian politicians hold Australian science.

Peter Hunt

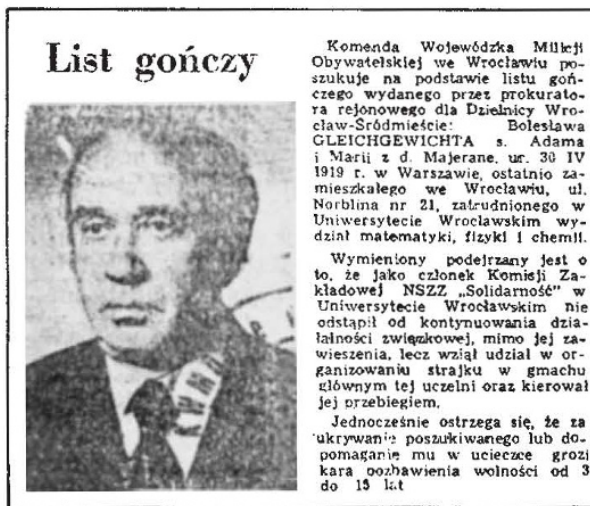

\title{
US plant patent disputed
}

A fierce protest against the validity of a US patent dealing with plant breeding has been made public by Professor N.L. Innes, chairman of the British Association of Plant Breeders and a member of the staff of the British National Vegetable Research Station. The patent complained of was awarded in April this year to the Colorado based corporation Agrigenetics Research Associates, a seed firm with annual revenues of $\$ 100$ million.

The invention for which the patent has been awarded is described in the published version (US patent number $4,326,358$ ) as a technique for accelerated production of new hybrid strains of plants and rapid commercial production of seeds from such hybrids. The patent claims that seeds of desirable new hybrids can be readied for marketing in as little as three years rather than the present eight to twelve years.

In conventional hybrid production, the plant breeder first has to breed two different homozygous plant lines from which a hybrid is produced and tested. Not only can it take many years to breed the homozygous lines but homozygous plants often produce low numbers of seeds.

In its essentials the invention covered by the patent starts with the crossing of any heterozygous plant - of which there is a great variety of good seed producers with a heterozygous or homozygous partner. The hybrid offspring of such a cross will not be genetically identical but, on occasion, the plants will still be sufficiently similar to be worth testing as a potential crop.

If they have desirable crop qualities, the breeder then returns to the parent plants and propagates them, asexually, as clones. The large numbers of each parent so generated are then crossed to produce large numbers of hybrids, equivalent to those of the original cross of the individual parents.

The protest from the British Association of Plant Breeders (published in full on page 786) boils down to the assertion that the use and advantages of heterozygous parental plants as breeding stock are well known and that clonal propagation of individual plants is now a standard technique in plant breeding, so that the particular combination of the two principles for which a US

"WANTED for continuing trade union activities under martial law, and for organizing a strike in Wroclaw University" says this notice from a recent issue of the Wroclaw daily Gazeta Robontnicza. Professor Boleslaw Gleichgewicht, the subject of this notice, is a leading Polish mathematician, a former organizer of the clandestine "Flying University" and one of the founder-members of the Wroclaw University chapter of Solidarity. He is now in hiding.

The notice includes a warning that the penalty for hiding or assisting the "fugitive" is from three to fifteen years loss of liberty. patent has been awarded must be obvious and thus not qualified for protection.

Even the combination of techniques described in the patent is very similar to that used in practice by, for example, British sugar beet breeders, says Dr Richard Macer, secretary of the British Association of Plant Breeders.

According to Rene Tegtmeyer, of the US Patent Office, to which Professor Innes has sent a copy of the letter, a formal request for reexamination can be filed after a patent is issued, but only on the grounds of a prior patent or publication that was overlooked by the patent office in its original examination. Prior public use or sale is not sufficient grounds for reopening an already-issued patent. Even in the original examination of an application, Tegtmeyer says, a foreign use would not bar patenting in the United States, although a foreign publication could.

"Any given detail or sequence may seem obvious, but the way they're put together may be original", so far as the patent law is concerned, says Dr David Padwa, chairman of Agrigenetics, who will shortly announce licensing terms that will be "fair and reasonable"'.

A second Agrigenetics patent, applying the techniques to a specific species, was recently allowed by the patent office and should soon be issued. Meanwhile Agrigenetics awaits the outcome of its application last January to the European Patent Office for a patent similar to the one issued in the United States.

\section{Australian patents bill Seeds of doubt}

\section{Canberra}

The Australian government's first attempt to legislate for the protection of new plant varieties has blown up in its face. The Plant Variety Rights Bill, introduced a year ago and passed by the House of Representatives in April, is now the focus of a political storm. And the Senate has referred the bill to its Standing Commission on Natural Resources, a procedural device for postponing a decision.

The objective of the bill, of crucial importance in a country with a large agriculture industry, is to enable plant breeders to acquire the same kind of proprietary rights in new plant varieties as have long been available in some European countries. The present Patents Act, dependent as it is on the criterion of reproducibility, does not protect most plant varieties.

Five years ago, the Australian Agricultural Council (a political body representing federal and state ministers) recommended legislation on plant varieties protection with the objectives of stimulating the commercial plant breeding 